\title{
GÊNERO, CONJUGALIDADES E REPRODUÇÃO MEDICAMENTE ASSISTIDA: ASPECTOS REGULATÓRIOS E PRÁTICAS EM DIFERENTES CENÁRIOS
}

\author{
Luciane Moás \\ Eliane Vargas ${ }^{2}$
}

\section{RESUMO}

0 artigo focaliza a construção das práticas reprodutivas no acesso à reprodução assistida na qual a sexualidade conjugal, a dinâmica familiar e as instâncias regulatórias se encontram imbricadas. Considerando a dimensão cultural e simbólica intrínseca à produção dos corpos, os processos identitários na cena contemporânea colocam desafios à concretização do desejo de filhos no âmbito das conjugalidades hetero ou homossexual. Abordam-se as regulamentações e instâncias decisórias relativas ao uso de tecnologias reprodutivas, bem como os elementos presentes na dinâmica conjugal que envolvem o desejo de uma reprodução "natural" via tecnologias médicas. Observa-se operarem parâmetros médicos e jurídicos prescritivos que não correspondem à experiência dos casais e indivíduos que recorrem às tecnologias de reprodução medicamente assistida.

Palavras-chave: Corpo reprodutivo. Gênero. Sexualidade conjugal. Tecnologia Reprodutiva.

\footnotetext{
${ }^{1}$ Professora do Departamento de Ciências Jurídicas da Universidade Federal Rural do Rio de Janeiro,Brasil.lumoas@yahoo.com.br

${ }^{2}$ Pesquisadora do Instituto Oswaldo Cruz da Fundação Oswaldo Cruz, Docente da Pós-Graduação em Ensino em Biociências e Saúde/IOC/Fiocruz e da Pós-Graduação em Saúde Pública da Escola Nacional de Saúde Pública (ENSP/FIOCRUZ), Brasil. elianepvargas@gmail.com
} 


\section{GENDER, CONJUGALITIES AND ASSISTED REPRODUCTIVE TECHNOLOGIES: REGULATORY ASPECTS AND PRACTICES IN DIFFERENT SCENARIOS ABSTRACT}

The present article focuses on the construction of the reproductive practices in the access to assisted reproduction in which the conjugal sexuality, family dynamics and regulatory instances are intertwined. Considering the cultural and symbolic dimension inherent to the production of bodies, the identity processes in the contemporary scene pose challenges to the realization of the desire for children both under the heterosexual and homosexual conjugalities. Regulations and decision-making issues regarding the use of reproductive technologies are addressed, as well as the elements present in the marital dynamic involving the desire for a "natural" reproduction via assisted technologies. Prescriptive medical and legal parameters that do not match the experience of couples and individuals who turn to assisted reproductive technologies were found in this work.

Keywords: Reproductive body. Gender. Conjugal sexuality. Reproductive Technology.

\section{INTRODUÇÃO}

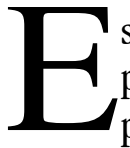

ste trabalho $0^{3}$ focaliza na cena contemporânea expressões das relações de poder entre produção dos corpos, intervenções biomédicas e tratamentos por meio das técnicas de reprodução humana assistida (RA) em um contexto de reivindicação de direitos ${ }^{4}$. Busca contemplar as implicações dos usos das tecnologias reprodutivas para a existência individual e coletiva considerando as atuais proposições no plano dos direitos à filiação, não somente através da adoção,

\footnotetext{
3 Resulta de versão aprimorada com incorporação das discussões realizadas a partir da apresentação do paper intitulado: "Entre o natural e o espontâneo: intervenções tecnológicas sobre o corpo reprodutivo e dimensões da sexualidade conjugal", no XVI Congresso Brasileiro de Sociologia - 10 a 13 de setembro de 2013, Salvador (BA). Agradecemos as valiosas contribuições dos/das pareceristas e de Martha Ramírez-Gálvez, na qualidade de organizadora, para 0 aprimoramento do texto e, sobretudo, pela possibilidade de interlocução.

${ }^{4}$ Duas pesquisas se somam na elaboração deste artigo. Uma diz respeito a dados sobre o uso de tecnologias reprodutivas com casais heterossexuais (RJ) e a outra acompanha o debate sobre demandas judiciais envolvendo a conjugalidade homossexual e a ampliação de direitos da população LGBT, com incorporação do debate sobre a criminalização da homofobia. As análises conjugam a literatura das ciências sociais nas interfaces com outros campos do saber e, sobretudo, com uma visão critica de documentos normativos a partir da área do Direito. As pesquisas contaram com apoio financeiro do Apoio CNPq e Faperj.
} 
mas principalmente, pela possibilidade cada vez maior por parte dos casais e indivíduos de diferentes orientações sexuais de recurso às técnicas de reprodução medicamente assistida visando a concepção. Nesta questão está implicada a decisão do Supremo Tribunal Federal (STF), proferida em maio de 2011, que reconheceu as uniões estáveis homoafetivas como entidades familiares, portanto, com os mesmos direitos conferidos à conjugalidade heteroafetiva. Destaca-se, principalmente, a recente resolução do Conselho Federal de Medicina, de n.2013/2013 que, ao revogar a resolução anterior, de n. 1957/2010, faz referência expressa à possibilidade de acesso a essas tecnologias pelos casais homoafetivos.

Apesar de já ser considerável a produção acadêmica sobre reprodução assistida no Brasil é relevante ressaltar que este debate não tem sido considerado prioritário na cena pública. Ao contrário, o tema se encontra quase completamente invisibilizado nas agendas governamentais e de políticas públicas, sobretudo da saúde (VARGAS \& MOÁS, 2014). A ausência de debate público no Brasil ${ }^{5}$ e 0 fato de não ser assunto prioritário na discussão sobre políticas públicas de saúde, justificam a necessidade de desdobramentos das pesquisas na medida em que verificamos certo descompasso quando analisamos os diferentes discursos relacionados aos seus contextos de produção. Hoje já se pode dizer tratar-se de um cenário comum o uso de tecnologias para fins reprodutivos, como já analisado por outros autores em diferentes perspectivas (NOVAES \& SALEM, 1995; SALEM, 1995; STOLCKE, 1998; CORRÊA, 2001; LUNA, 2001; DINIZ 2002; RAMÍREZ-GÁLVEZ, 2003; GROSSI et al, 2003; TAMANINI, 2009; 2013) com os quais a presente reflexão vem se somar.

0 artigo está organizado em três partes. A primeira e segunda partes apresentam reflexões sobre os aspectos regulatórios que permeiam a decisão reprodutiva no âmbito das diferentes conjugalidades e práticas reprodutivas plurais. Nesta direção localiza a posição do Supremo Tribunal Federal (STF) e as normas "éticas" do Conselho Federal de Medicina (CFM) no que concerne ao tema, considerando o lugar decisório que estas instâncias ocupam no cenário social. A terceira parte expõe, a partir da experiência de casais heterossexuais, as aporias relativas à ideia de reprodução como "acontecimento natural" e de sexualidade espontânea presentes nestas experiências, uma vez que tais

${ }^{5}$ Este aspecto já foi apontado por Diniz (2002) e permanece atual. 
concepções naturalizadas se apresentam sobrepostas aos tratamentos médicos altamente tecnológicos no universo investigado ${ }^{6}$.

\section{ENTRE DIREITOS PRESCRITIVOS E PRÁTICAS REPRODUTIVAS PLURAIS}

Em razão da inexistência de lei sobre reprodução assistida ainda persistente no Brasil, velhas questões continuam sendo discutidas no cenário jurídico, embora com menos intensidade que em passado recente. Pode-se considerar que algumas das questões em tela presentes neste debate podem alcançar, em termos de regulações, tanto a indivíduos quanto casais, independentemente da orientação sexual ainda que se compreenda existirem especificidades modeladoras das práticas reprodutivas nestes diferentes contextos. As principais questões comuns, em torno das quais os debates orbitam, são: 1) A possibilidade ou não de se utilizar material fecundante de terceira pessoa alheia ao projeto parental daqueles que lançam mão das técnicas; 2) A importância da utilização de documentos (e 0 valor legal dos mesmos) que possam atestar com certeza e clareza do tipo de participação e manifestação de vontade correspondente neste processo. É o caso, por exemplo, do parceiro(a) que autoriza o procedimento, assumindo apenas a paternidade socioafetiva e, na hipótese de eventual arrependimento, não poder deixar de reconhecer a criança; 3) 0 sigilo dos doares de gametas e embriões; 4) As consequências da reprodução post mortem; dentre outras. A problematização destas questões que envolvem considerações específicas tem sido encontrada em inúmeros artigos científicos da área jurídica, mas escapa aos objetivos deste trabalho.

No que concerne à ampliação da discussão em torno dos direitos civis no Brasil, quanto à regulamentação das relações entre pessoas do mesmo sexo no que tange à reprodução, trata-se de um novo contexto no qual o agenciamento pelos indivíduos e casais se realiza mediante o uso dos recursos médicotecnológicos, com vistas à filiação e constituição de família. No que se refere ao desejo de filiação, esta discussão aponta também o surgimento de novas conjugalidades e de exercício de maternidade e paternidade em um contexto de transformação de valores relativos à constituição de família, não somente via adoção, mas também pelo uso de recursos biomédicos.

\footnotetext{
${ }^{6}$ A dinâmica da conjugalidade homossexual envolvendo a experiência reprodutiva via tecnologias médicas não foi contemplada no estudo e, de nosso ponto de vista, ainda tem sido pouco estudada constituindo-se em interesse de desenvolvimentos futuros.
} 
Vale ressaltar que a decisão contemporânea de ter filhos e/ou "poder ter filhos", como enuncia quem os deseja, aponta mudanças, mas também permanências de valores relativos ao gênero e às relações familiares em meio às referências e às imbricações das relações entre natureza e cultura presentes na expressão do desejo de filhos envolvendo a tecnociência. Consideramos, neste sentido, que os arranjos e práticas reprodutivas plurais se sobrepõem aos discursos produzidos - notadamente os saberes médico e jurídico por sua função normativa - incluindo os das políticas públicas de saúde, evidenciando algumas facetas das articulações entre corpo, gênero e tecnologias presentes neste debate?. Apresenta-se, portanto, como objeto de interesse a análise dos nexos entre a sexualidade e a reprodução envolvendo as tecnologias reprodutivas neste novo cenário de constituição do par conjugal e de arranjos familiares.

As análises no âmbito das ciências sociais sobre a maternidade e a paternidade, em diferentes níveis das práticas reprodutivas, exemplificam as transformações e permanências de valores relativos à constituição de família assinaladas (KNIBIEHLER, 2001). Pesquisas sobre maternidade e paternidade fora do casamento entre solteiros heterossexuais, via adoção ou reprodução biológica (COSTA, 1988; DAUSTER, 1988) constituem exemplo destas transformações, bem como a reivindicação de paternidade homossexual (UZIEL, 2002; TARNOVSKI, 2004; MELLO, 2005) tem merecido a atenção de pesquisadores do campo. Seja pela via da adoção ou reprodução biológica, estes estudos apontam nos pais e mães solteiros a constituição de novos arranjos familiares que se apresentam como alternativas à constituição do casal e, é interpretado, por vezes, como uma expressão da ideologia individualista nas relações familiares (PEIXOTO, 2000).

No que tange às leis e saberes jurídicos são variados os modelos reconhecidos pelo ordenamento jurídico, logo, protegidos pelo Estado (MORAES, 2010). No entanto, no estudo da família homoafetiva, mas também heterossexual, e em algumas abordagens de áreas do saber, o foco permanece no direito à filiação, inegavelmente questão ainda sensível neste debate.

Cabe lembrar que o ordenamento jurídico brasileiro considera também a filiação ${ }^{8}$ quanto ao seu aspecto cultural, ou seja, decorrente da afetividade, da

\footnotetext{
${ }^{7}$ A problematização das dicotomias e distinções presentes nas relações entre natureza e cultura relacionadas a eventos reprodutivos tem sido empreendida por autores brasileiros como Manica (2011) em contexto de atuação médica, produção de tecnologias e ressignificação de seus usos; e Luna (2001) acerca dos impactos das tecnologias nas relações de parentesco.

${ }^{8}$ Destaque-se que desde a Constituição Federal de 1988 a filiação é um conceito único não comportando as adjetivações comuns no passado: filho legítimo, ilegítimo, natural, adotivo,
} 
convivência familiar como "fenômeno socioafetivo", não considerando apenas a origem biológica (FONSECA, 2004) ${ }^{10}$. Não obstante tratar-se de processo ainda em construção, pois durante muito tempo esta dissociação entre a "verdade do sangue" e o vínculo jurídico (paternidade definida no registro de nascimento) era experimentada apenas pela adoção. A utilização crescente da reprodução assistida tornou possível ressignificar as relações de parentesco, que foram abaladas ao se considerarem os critérios que as apoiam e comportando, deste modo, outra origem além da adoção.

0 vínculo contemporâneo entre pais e filhos diz respeito à identidade da filiação, tecida na complexidade das trocas afetivas que são construídas no tempo e decorrem da liberdade e do desejo de exercer a função social de pai e de mãe. 0 Direito à convivência familiar, assegurado pela Constituição Federal de 1988 e pelo Estatuto da Criança e do Adolescente (Lei 8069/90), como interesse prioritário, tem por base as relações afetivas e não a origem biológica. De acordo com a literatura deste campo, o equilíbrio entre o vínculo biológico e o socioafetivo é desejável na construção da nova família e na emissão de julgamentos que evitem omissões:

Atualmente, o filho é mais que um descendente genético e se revela numa relação construída no afeto cotidiano. Em determinados casos, a

adulterino, incestuoso, etc. A igualdade jurídica entre todos os filhos, questão bastante evidente atualmente, é fruto de longa e lenta conquista, pois as classificações acima indicadas implicavam na restrição de direitos tendo como referência a família patriarcal - modelo prevalente até àquela data.

9 0 termo "socioafetivo" tem sido empregado no debate do Biodireito envolvendo tecnologias reprodutivas, o que inclui as uniões homoafetivas. No entanto, estas denominações não coincidem necessariamente com as autoclassificações oriundas do movimento social LGBT. Esta questão foi objeto de debate no XVI Congresso Brasileiro de Sociologia (vide nota 1), no qual foram assinaladas as tensões e limitações derivadas dos usos dos termos "homoafetivo" e "homoerótico" na compreensão das práticas sexuais e do exercício da sexualidade conjugal.

${ }^{10} 0$ sistema Civil Brasileiro passou a dar maior valor ao parentesco biológico após o advento do exame de DNA, capaz de apontar "a verdade" consangüínea pela certeza bastante elevada oferecida por esta tecnologia, a partir dos anos 1960. Antes, a determinação da paternidade era estabelecida com base em presunções que visavam proteger a família legítima (aquela que se constituía através do casamento). Se a maternidade era sempre certa ("mater semper certa est") em razão da evidência do parto, a paternidade que podia ser incerta era estabelecida pela presunção "pater is est quem nupciae demonstrant": pai é aquele indicado pelo casamento da mãe da criança, ou seja, quando a mulher é casada presume-se que o filho nascido durante o casamento é de seu marido. Trata-se de presunção relativa, podendo ser afastada através da ação negatória da paternidade ajuizada pelo marido. 
verdade biológica cede espaço à "verdade do coração". (...) Em matéria de família, o julgador tem papel de relevo indiscutível. Por ações ou omissões, os pronunciamentos do Judiciário acabam edificando, a seu modo, um novo conceito de família (FACHIN, 2006, p. 193).

0 estado de filiação não se confunde com 0 direito ao conhecimento da origem genética, do qual toda pessoa, apenas em princípio, é titular. Trata-se de legítimo interesse moral do indivíduo, desde que possível, conhecer sua origem ou história pessoal. É este o sentido da nova lei de adoção (12.010/2009), ao estabelecer no art. 48 que:

0 adotado tem direito de conhecer sua origem biológica, bem como de obter acesso irrestrito ao processo no qual a medida foi aplicada e seus eventuais incidentes, após completar 18 anos.

Parágrafo único: 0 acesso ao processo de adoção poderá também ser deferido ao adotado menor de 18 anos, a seu pedido, assegurada orientação e assistência jurídica e psicológica. ${ }^{11}$ (BRASIL, 2009, p 3-4)

Há de se ponderar sobre os variados sentidos presentes na questão da filiação e do conhecimento da origem, a depender das diferentes relações, combinações e arranjos possíveis por meio do recurso às tecnologias reprodutivas (maternidades e paternidades homo/hetero; RA heteróloga em que houve doação de material genético masculino e feminino de ambos ou de um deles), não abordadas especificamente neste artigo. No entanto, em uma perspectiva jurídica, o direito à ascendência genética de certa forma está vinculado ao direito à vida, em razão da insuperável relação entre eventuais necessidades de medidas preventivas de saúde e ocorrências de doenças em parentes próximos. Neste aspecto, no que tange especificamente à legislação brasileira, não há total simetria entre a adoção e a reprodução assistida heteróloga na medida em que a normativa do Conselho de Federal de Medicina (Resolução 2013/2013), continua garantindo o sigilo sobre a identidade dos doadores de gametas e embriões, bem como dos receptores, resguardando a identidade civil dos envolvidos. Segundo a orientação ética, apenas em situações excepcionais, por motivação médica, as informações sobre os doadores podem ser fornecidas exclusivamente para os médicos.

\footnotetext{
${ }^{11}$ É importante destacar que o direito de conhecer a origem genética não acarreta qualquer reflexo na relação de parentesco, notadamente na esfera patrimonial, a exemplo do direito sucessório ou da possibilidade de pleitear alimentos. Todavia o vínculo de parentesco constituído através da adoção é irrevogável.
} 
Ao considerarmos 0 ordenamento jurídico francês, este assegura a possibilidade de a mulher, ao dar à luz ao filho, exigir que sua identidade não seja aposta no registro de nascimento da criança e que o filho não possa demandá-la para atribuir-lhe a maternidade. Assim, permite o apagamento dos traços de identidade dos pais biológicos, prática conhecida como parto anônimo ${ }^{12}$. Em certa medida, nosso ordenamento jurídico admite tal prática que se aproxima muito deste procedimento: a lei de adoção permite que após o nascimento a criança seja entregue para a adoção, sem que isto implique em alguma penalidade ou constrangimento para a mulher. Mas, como analisa Fonseca (2009), questões de moralidade relacionadas ao exercício da maternidade estão envolvidas neste eventos como 0 abandono, o aborto e a adoção. Assim, fazer coincidir a filiação com origem genética é transformar este fato em determinismo biológico, o que não contempla suas dimensões culturais e sociais (PEREIRA, 2011).

\section{INSTÂNCIAS DECISÓRIAS: A POSIÇÃO DO SUPREMO TRIBUNAL FEDERAL E AS NORMAS “ÉTICAS” DO CONSElHO FEDERAL DE MEDICINA EM NOVOS CENÁRIOS}

A crescente visibilidade da conjugalidade homossexual acarretou importantes conquistas no plano dos direitos civis ${ }^{13}$. A entrada dos homossexuais na arena política contribuiu para a disseminação da ideia de casamento como uma construção sociocultural dinâmica, mutável e capaz de incorporar modos diversos de manifestações afetivo-sexuais entre os indivíduos. No entanto, como toda trajetória de lutas reivindicatórias é marcada por avanços e retrocessos, 0 reconhecimento da categoria "família homoafetiva" somente ocorreu

${ }^{12}$ Segundo Lôbo (2012, p. 227), por iniciativa do IBDFAM (Instituto Brasileiro de Direito de Família), foi protocolado o projeto de lei 3320/2008, visando regulamentar o parto anônimo no país. Caso fosse transformado em lei, a mulher isentar-se-ia de qualquer responsabilidade civil ou penal e poderia solicitar 0 anonimato durante o pré-natal ou o parto ao estabelecimento de saúde, que deveria informar o nascimento no prazo de vinte e quatro horas ao juizado da infância e juventude, para registro provisório e encaminhamento à adoção. De acordo com a exposição de motivos, a finalidade era diminuir a clandestinidade dos abortos e evitar 0 abandono de recémnascidos em lugares que acabam por acarretar sua morte. Além disso, incentiva-se a adoção sem que a criança precise passar por abrigos provisórios. Para a maior parte dos estudiosos do tema tal PL era desnecessário, motivo pelo qual foi arquivado em 2012.

${ }^{13}$ A resolução aprovada pelo Conselho Nacional de Justiça (CNJ) diz que: "É vedada às autoridades competentes a recusa de habilitação, celebração de casamento civil ou de conversão de união estável em casamento entre pessoas de mesmo sexo". E acrescenta que, se houver recusa dos cartórios, será comunicado o juiz corregedor para "providências cabíveis". Fonte: Jornal Estadão, de 14.05.2013. 
recentemente, em maio de 2011, quando o Supremo Tribunal Federal (STF) equiparou esta convivência às uniões estáveis heterossexuais, rompendo de uma vez por todas com os limites heteronormativos no plano dos direito, como também com a crença arraigada de que a família e o casamento são realidades sociais intrinsecamente associadas à vinculação afetivo-sexual entre um homem e uma mulher.

0 Supremo Tribunal Federal (STF) abriu a possibilidade de reconhecimento de nova reconfiguração da família a partir da indicação da ausência de distinção entre as entidades familiares, seja 0 par hetero ou homossexual. Com isto contribuiu para a retomada do debate sobre homoparentalidade. É neste âmbito da filiação que retomamos a questão do poder normatizador do CFM que baliza os parâmetros éticos da prática de reprodução assistida, porém, não se restringe a eles. Deparamo-nos com a iniciativa do CFM no sentido de atualizar as orientações da prática de RA, sendo que todas as resoluções tratam de pontos emblemáticos, diretamente relacionados com as implicações éticas do acesso dos casais tanto heterossexuais quanto homossexuais às técnicas (MOÁS \& VARGAS, 2012). No que toca ao acesso às técnicas de RA, a resolução $n^{0}$ 1957/2010 apenas de forma implícita já havia avançado no debate, reacendendo a discussão acerca da possibilidade procriativa entre homossexuais, pois estabelecia que todas as pessoas capazes, solicitantes do procedimento e cuja indicação não se afastasse dos limites da própria resolução, podiam ser receptoras das técnicas de RA, desde que de inteiro acordo e devidamente esclarecidas.

A normativa mais recente, do ano de 2013, foi expressa sobre a possibilidade de acesso de casais de mesmo sexo à RA. Apresentando a decisão do STF acima referida como justificativa, estabeleceu no item II: "é permitido o uso das técnicas de RA para relacionamentos homoafetivos e pessoas solteiras, respeitando o direito de objeção de consciência do médico". E no item VII - sobre a gestação de substituição (doação temporária do útero) estabeleceu: "as clínicas, centros ou serviços de reprodução humana podem usar as técnicas de RA para criarem a situação identificada como gestação de substituição em caso de união homoafetiva”. Da mesma forma, as duas resoluções autorizam a maternidade de substituição (doação temporária do útero), desde que exista problema médico que impeça ou contraindique a gestação na doadora de material genético. Mas, a resolução mais recente (2013) amplia o grau de parentesco. Enquanto a resolução revogada estabelecia que as doadoras temporárias devessem ser parentes até o segundo grau, contemplando apenas a mãe, a sogra ou a irmã, a resolução de 2013 trabalha com o parentesco consanguíneo até o quarto grau 
(primeiro grau - mãe/sogra; segundo grau - irmã/avó; terceiro grau - tia; quarto grau - prima), em todos os casos, respeitada a idade limite de até 50 anos.

Além disso, ainda na parte referente aos princípios gerais estabelece que 0 número máximo de oócitos e embriões a serem transferidos para a receptora não pode ser superior a quatro. Quanto ao número de embriões a serem transferidos faz as recomendações considerando, mais uma vez, o critério da idade. Para mulheres com até 35 anos: até dois embriões; em mulheres entre 36 e 39 anos: até três embriões; em mulheres entre 40 e 50 anos: até quatro embriões. Nas situações de doação de óvulos e embriões, determina seja considerada a idade da doadora no momento da coleta dos óvulos.

Para além destas tensões que envolvem estas normativas e resoluções, há outras questões controversas. Uma delas reside no fato de todas as orientações sugerirem 0 uso da RA mediante probabilidade efetiva de sucesso e ausência de risco grave de saúde para a paciente e/ou o possível descendente, além de desconsiderarem os aspectos subjetivos ligados à experiência íntima dos casais. Estas normativas por si só são discutíveis, pois, apesar dos inegáveis avanços científicos, não se pode ter certeza sobre a eliminação dos riscos nem excluir os aspectos subjetivos, de todo modo culturais, que envolvem os usos tecnológicos neste campo. As tecnologias reprodutivas, como oferta de recursos (STRATHERN, 1992) ampliaram a liberdade de escolha das famílias. No entanto, são criadas e apoiadas na construção de imagens refinadas em torno das técnicas que proporcionarão aos seres humanos somente benefícios. Nestes termos, a procriação pode agora ser pensada também como preferência pessoal que não corresponde, contudo, necessariamente a escolhas aceitáveis ou consideradas "boas" no sentido de um consenso social para os indivíduos envolvidos.

Nesta direção aspectos subjetivos implicados na dimensão destas escolhas se diferenciam daqueles presentes na noção de risco, nos moldes que norteiam os critérios biomédicos ${ }^{14}$, como veremos a seguir no que concerne aos constrangimentos da atividade sexual mediante os procedimentos médicos adotados a partir das narrativas dos casais. Sem pretendermos ser exaustivas,

${ }^{14}$ Luna (2001), p. ex., aponta outros riscos ligados aos valores relativos ao parentesco e à constituição da família que diferem em grande medida daqueles considerados de um ponto de vista biológico. Estes não serão tratados aqui. 
assinalaremos as marcas de pertencimento cultural no exercício da sexualidade heterossexual no contexto da $\mathrm{RA}^{15}$.

\section{REPRODUÇÃO NATURAL VERSUS ARTIFICIAL SEXUALIDADE ESPONTÂNEA E SEU REVÉS: “TRANSAR PARA ENGRAVIDAR”}

Para apontarmos as intervenções tecnológicas no corpo decorrentes do uso das tecnologias reprodutivas, trazemos aqui especificamente alguns aspectos constitutivos da dinâmica sexual conjugal heterossexual envolvendo a decisão de ter filhos mediante a RA, a partir de situações de infertilidade medicamente falando (VARGAS, 2006). Cabe considerar que o acesso aos casais não constitui tarefa fácil nesse tipo de estudo. 0 segredo sobre os assuntos tratados neste tipo de pesquisa é uma dimensão relevante relacionada ao tema, uma vez que uma sensibilidade em torno da vida íntima está muito presente nas narrativas, como apontado nas pesquisas já citadas. Assim, cabe considerar, no que concerne aos pressupostos das análises voltadas às áreas da sexualidade, da família e da reprodução - envolvendo ou não o uso de tecnologias reprodutivas, que a experiência reprodutiva e sexual contemporânea enfatiza a primazia da liberdade de escolha, a promoção da autonomia e a interiorização como referências relevantes para este universo.

Chamamos a atenção, por conseguinte, que se sobrepõem à decisão reprodutiva no âmbito conjugal 0 anseio dos casais em conceber um filho de modo "natural", entendido aqui como um "filho do próprio sangue", e uma predisposição à manutenção de relações sexuais "espontâneas" dissociadas da reprodução. A "atividade sexual regular" é considerada um parâmetro inicial e importante na avaliação médica da 'infertilidade conjugal' e tida como um $a$ priori da relação conjugal. Nos casais da pesquisa, o tempo de relação conjugal variou entre sete e treze anos, indicando a condição de "casais estabilizados" como analisado na literatura (BOZON, 2001). Em alguns casos ocorreu um longo período de namoro (13 e 15 anos) antes do casamento. Cabe, portanto, considerar a tendência à diminuição da atividade sexual em casais estabilizados como os da pesquisa, o que poderia estar acarretando uma diminuição das chances de engravidar. Nesta direção o exercício sexual induzido "medicamente falando" no caso, por exemplo, da realização de testes pós-coito ou do coito planejado pelo par

150 caráter "invasivo" das intervenções médicas e tecnológicas, não especificamente relacionado ao exercício da sexualidade, foi referido por solicitantes da adoção como aponta Ramírez-Gálvez (2011). 
conjugal com o objetivo de reproduzir - "transar para engravidar", resulta em contrariar não só determinadas expectativas de desempenho da atividade sexual "espontânea”, mas também de reprodução "natural”, uma vez que são assim concebidas pelos casais.

Entre os casais da pesquisa voltada para casais heterossexuais, a perspectiva de constituição de uma família biológica demonstrou ser uma tendência forte e o desejo de filhos se delineou como uma decisão racional, e ao mesmo tempo um evento "natural" e "espontâneo" que consolida o laço conjugal associando-o à formação da família ${ }^{16}$. Embora a adoção visando a constituição de família e de filiação estivesse presente entre os casais hetero entrevistados, tal via parece inviabilizar a concepção de filho legítimo proporcionado pela RA. RamírezGálvez (2011) torna a questão mais complexa ao propor a análise do processo de adoção de crianças relacionada ao de adoção de pré-embriões, este último já tematizado no campo das tecnologias reprodutivas, mas visto como problemática em separado. 0 tema da adoção e seus variados sentidos especificamente não serão tratados aqui.

Nosso intuito foi o de assinalar brevemente a relevância dos "laços de sangue" no que tange ao desejo de filiação. No entanto, ainda que de forma restrita, ressaltamos que a via proposta pela autora nos parece ser interessante e fecunda para se avançar 0 debate acerca de determinadas configurações simbólicas presentes em outros campos, além da RA, visto que estas têm sido tratadas de modo isolado. Nesta direção, consideramos também as ponderações de Costa (1988) sobre a abordagem da adoção em um passado recente. A autora ao reunir numerosos casos de adoçã $0^{17}$ visando a análise das representações de adoção no universo de camadas médias brasileiras, sugeriu que a abordagem deste tema naquele momento foi apenas marginal em textos que tratavam de parentesco ou se apresentou como registro de etnografias clássicas estudadas.

De fato a RA permite a realização da concepção como um "processo natural", mas, este recuso introduz paradoxos neste tipo de experiência. Se, por um lado, o recurso aos procedimentos médicos é uma escolha, por outro, tal

\footnotetext{
${ }^{16}$ Souza (2006) observou entre mulheres lésbicas unidas canadenses alguns diferencias presentes na prática reprodutiva (exclusão masculina da concepção e co-parentalidade com parceira que não possui vínculo com a criança, por exemplo) que, no entanto, são rearranjadas em um modelo muito semelhante ao da família nuclear heterossexual

${ }^{17}$ De acordo com Ramírez-Gálvez (2011) este cenário mudou. 0 número de adoções legais concedidas no Estado de São Paulo (1994-2004) vem apresentando uma progressiva e constante diminuição.
} 
escolha implica, em alguns casos, em uma interferência na atividade sexual - que tende a ser percebida como incômoda, indesejada e "invasiva" -, uma vez que idealmente é concebida como livre expressão da autonomia do indivíduo, como veremos nos depoimentos mais adiante. Na narrativa dos casais heterossexuais 0 termo "invasão" não esteve vinculado somente à experiência com os tratamentos, mas também referida à dinâmica das relações com a família de origem. As atitudes dos parentes, em geral, são consideradas invasivas. As relações com a família de ambos os cônjuges refletem certo tipo de tensão, como emerge das narrativas, podendo ser identificadas interferências na relação conjugal, sobretudo a pressão exercida sobre o par conjugal para conceber, o que foi considerado uma "invasão" de privacidade na decisão reprodutiva do casal.

os casais heterossexuais no contexto da pesquisa tenderam a não conversar com suas famílias de origem sobre o problema ou participá-los "passo-a-passo" de suas intenções ou decisões. Esta tendência variou, em se tratando de relações mais próximas ou mais distantes, entre irmãos, pais, sobrinhos, cunhados, sogras e sogros. Uma mulher relatou ter encoberto a realização dos exames de familiares para tentar minimizar a participação destes na cena; outra julgou que a chegada do filho esperado não despertaria tanto interesse de seus sogros, pois já havia muitas crianças na família. No entanto, surpreendeu-se ao reconhecer que eles estavam "desesperados" para que o casal tivesse filhos. Eles sofriam juntos, sabiam e "acompanhavam" a situação, mas não era usual conversarem sempre sobre 0 assunto com eles (seja da família de origem dele ou dela). Outra entrevistada, por sua vez, não viu com bons olhos o compartilhamento com 0 irmão e a cunhada do marido, também dedicados à tarefa de conceber, pois para ela foi "uma tentativa deles serem sócios nos problemas", reafirmando tratar-se de uma questão exclusivamente do casal.

Cabe notar a existência de oscilações entre os comportamentos familiares menos ostensivos e mais acolhedores nas famílias "mais relaxadas", ou mais provocadores nas famílias mais "invasivas", entre os casais heterossexuais. No entanto, a grande expectativa, o intenso envolvimento dos parentes - pelas referências aos apoios afetivos e eventuais apoios financeiros, - as opiniões e uma atenção voltada para os casais, ainda que envolto em silêncios e tentativas deles de distanciamento da família de origem no processo de concepção, revelam o quão ainda é relativa a autonomização do par conjugal em relação à rede de parentesco (PEIXOTO, 2000; DE SINGLY, 2000).

Se, de um lado, a concepção vista como assunto privado e íntimo é valorizada como evento "natural"; de outro, a sexualidade como experiência 
"natural" e "espontânea" neste contexto se desfaz na medida em que a relação "rolava por obrigação" e não chegava a bons resultados, seja do ponto de vista da satisfação sexual ("não rola nem tesão"), seja da reprodução. Sobre este último, ainda que alguns casais, de acordo com os depoimentos de um homem e de uma mulher, tenham "tentado de tudo", ou seja, transar durante um mês consecutivo sem interrupções ou ter tido relações sexuais com "data marcada" (transar em períodos considerados fisiologicamente mais favoráveis à ocorrência da concepção), a mesma não se viabilizou. Outras tensões entre o par geradas pela atividade sexual compulsória também foram observadas, como no caso do marido que apontou na mulher a razão de não ocorrer a gravidez porque o casal "transava pouco". Ela, por sua vez, auto responsabilizava-se pelas "coisas" que estaria ou não fazendo - como não ficar deitada por muito tempo e se lavar rapidamente após a relação sexual etc. -, que dificultava a viabilidade da concepção (VARGAS, et al., 2010).

Particularmente em relação aos homens, a realização de exames envolve grandes constrangimentos, mas são menos visíveis e problematizados mencionados de modo diferente pelas mulheres que tendem a considerar os procedimentos dolorosos - e pouco se sabe sobre os significados a eles atribuídos (VARGAS et al., 2010). Sob este aspecto cabe considerar que a "posição ginecológica”, como mencionado pelas entrevistadas, já é prática corrente entre as mulheres largamente submetidas a este tipo de exame médico. Sugerimos que ainda que o exame ginecológico envolva constrangimentos, trata-se de uma prática "naturalizada". Como se vê, o que se apresenta aos nossos olhos como absolutamente "subjetivo" e experiência singular contém as marcas dos discursos sociais sobretudo produzidos pela biomedicina.

Nesta direção destacamos que discutir os elementos em jogo nas instâncias decisórias, jurídicas ou médicas, que envolvem a decisão de ter filhos, não significa perder de vista 0 plano da experiência de indivíduos e grupos. Faz-se necessário considerar o modo de difusão dos discursos construídos em torno da reprodução assistida que carece de aparato legal e jurídico para 0 seu desenvolvimento, mas que não impede sua expansão. Como já indicado, atualmente não há lei em sentido formal (discutida, votada e aprovada através de regular processo legislativo) sobre reprodução assistida. Desde 1990, existem projetos de lei sobre o tema, em tramitação no Congresso Nacional.

Tendo o primeiro bebê de proveta brasileiro nascido em 1984, vigora na atualidade a resolução $n^{0}$ 2013/2013 do Conselho Federal de Medicina. Inova ao estabelecer que as técnicas têm o papel de auxiliar na resolução dos problemas 
implicados no processo de procriação, na medida em que possibilita a atuação dos médicos em outros casos, além daqueles decorrentes de causas patológicas clínicas. Apesar de ser possível considerar que esta resolução amplia a oferta reprodutiva, as resoluções do CFM efetivamente não têm força de lei. No entanto, mantém-se como a grande referência para a aplicação dessas técnicas na ausência de recurso legislativo disponível. Isto significa que as questões relativas ao acesso às técnicas e no plano dos direitos reprodutivos ainda se apresentam mediadas e geridas pelo discurso biomédico, o que reduz os amplos desafios que envolvem a reprodução humana contemporânea a uma questão de saúde.

Trata-se aqui de mecanismos que exploram e controlam o corpo (FOUCAULT, 1997), de modo que no cerne dos paradoxos das relações entre sexo e reprodução oscilam proposições entre "liberação" e "controle". Os discursos, portanto, sobre a reprodução que circulam na cena social parecem expressar alguns paradoxos: de um lado, advogam os direitos (sobretudo as mulheres) de ter filhos por opção, o que significa que elas tenham ao seu dispor as novidades do campo científico; de outro, vê-se tal reivindicação, que privilegia precisamente a reprodução biológica com base em uma concepção da reprodução como um fenômeno natural e físico, atrelado a um grande mercado de tecnologias e prescrições médicas que determinam seu resultado. Estes pressupostos reiteram uma visão da maternidade como parte e essência da identidade feminina e pressupõem um modelo universalista de família, em um contexto cultural fortemente centrado em um valor positivo da maternidade seja no contexto de conjugalidade hetero ou homossexual, ainda que não possa ser generalizável (VARGAS, 2012; SOUZA, 2006).

\section{NOTAS FINAIS}

É verdade que reproduzir se encontra no horizonte das possibilidades dos indivíduos e dos casais. É possível à mulher, ao homem e ao casal determinar (como e quando) ter um filho, ou não ter nenhum. 0 impensável para os casais que desejam filhos não é a ausência de filhos por opção (perfeitamente plausível enquanto uma escolha), mas a sua ausência involuntária - neste caso, limitados pela biologia -, ou seja, aquela que contraria a decisão autônoma do par conjugal. Tal experiência aponta um dos paradoxos neste contexto: 0 fato de que a subordinação da autonomia e da espontaneidade aos procedimentos médicos parece só se justificar por um ato de vontade, ou seja, pela afirmação do desejo ou da "vontade" de ter filhos. Este desejo, como referido, objetiva produzir, por intermédio de um extenso aparato tecnológico, uma gravidez como evento 
reprodutivo "natural" como também afirmado em outros contextos (MANICA, 2011). Frente à vontade soberana do indivíduo (a "escolha") parece, portanto, ser possível subordinar esse ideal de espontaneidade e liberdade às orientações e prescrições médicas visando a reprodução. Portanto, "decidir" e/ou "poder ter filhos" parece ter se tornado uma questão relevante para os casais contemporâneos marcados pelas transformações nas concepções de "família", pelos diferentes arranjos familiares e práticas reprodutivas, bem como pelos discursos em torno da reprodução humana no âmbito dos diversos saberes. Notadamente os saberes médico e jurídico desempenham uma importante função normativa sobre o tema, a partir dos diferentes atores envolvidos nesta temática.

No que diz respeito à construção da decisão reprodutiva, no que concerne aos dispositivos da lei e aos aspectos normativos, o planejamento familiar assegura que a reprodução é livre decisão do casal, competindo ao Estado propiciar recursos educacionais e científicos para o seu exercício, sendo vedada qualquer forma coercitiva por parte de instituições privadas ou públicas. Nesse sentido, os indivíduos são livres para planejar a filiação, o que abrange o momento (quando), o modo (como) e a quantidade que desejarem. No entanto, ainda que este direito esteja assegurado pela lei, sua realização plena (geração de filhos de origem genética conhecida e/ou desconhecida, por escolha afetiva, por meio de diferentes arranjos familiares ou, até mesmo, sem formação de família) apresenta-se distante da experiência dos casais homo e heterossexuais. Portanto, associado à decisão de ter ou não filhos um conjunto de valores se sobrepõem à racionalidade médica apontando aporias à ideia de opção no agenciamento de recursos tecnológicos.

Ainda no que diz respeito à decisão contemporânea de ter filhos considerando o universo de camadas médias (VARGAS, 2006), tal decisão corresponde a um projeto e escolha do casal individualizado e não mais à imposição que diz respeito à parentela. No entanto, em detrimento deste espectro de moralidades observa-se a presença marcante da família de origem quanto ao questionamento da ausência de filhos no âmbito conjugal que permeiam as interações de convívio familiar. Ademais, tal decisão reprodutiva parece subordinar valores como autonomia e espontaneidade, característicos deste universo sociocultural, a um extenso aparato tecnológico visando a reprodução, como se pretendeu assinalar. No universo em questão, tomando os dados da pesquisa (VARGAS, et al., 2010), os termos "privacidade" e "espontaneidade" se destacam como expressões obrigatórias do exercício da sexualidade contemporânea, o que evidencia entre os/as pesquisados/as o ideal da atividade 
sexual exercida de modo livre de constrangimentos, que contrasta com sua aquiescência/adesão à ordem ou racionalidade médica.

A categoria "casal" é de grande relevância na prática clínica da RA como já analisado por Tamanini (2009). Neste contexto abrange 0 englobamento masculino na problemática do diagnóstico da infertilidade, que historicamente envolveu de modo proeminente a mulher considerada em princípio infértil. Nesta mesma direção, e de acordo com os estudos nos quais se ancora a presente reflexão, "casal" não corresponde a uma categoria abstrata ou universal ${ }^{18}-$ como se apresentou no discurso biomédico sobre "casais inférteis" -, mas expressa fundamentalmente uma ênfase na dinâmica das complexas redes de relações sociais que integram a vida a dois.

Os casais heterossexuais da pesquisa que "não conseguem ter filhos" (VARGAS, 2006) apontaram que não se reconhecem como "inférteis": eles são "pessoas" que "tentam engravidar", não diferindo de nenhum outro indivíduo, independente da orientação sexual, com dificuldade de ter filhos. Em se tratando das camadas médias, portanto, com um capital cultural e com condições materiais de existência mais elevadas, encontram-se inseridos em um universo cultural que valoriza a "escolha" e a "liberdade" individual no que concerne às questões de trato íntimo. No universo das camadas populares também se encontra presente a dimensão da escolha na experiência reprodutiva, ainda que restrita pelas condições materiais de existência (VARGAS, 1999).

Portanto, falar sobre a dificuldade de conceber - por circunstâncias biológicas, econômicas ou por barreiras que se apresentam devido à orientação sexual -, com quem decidiu tê-los, muitas vezes implica para os casais e/ou indivíduos o enfrentamento de muitos desafios relacionados à garantia de direitos, entendida como expressão da dimensão da escolha e da liberdade individual no âmbito das leis, mas também às barreiras de acesso aos serviços médicos, sendo os serviços públicos e planos de saúde cada vez mais acionados devido aos altos custos dos procedimentos.

Tendo em vista que a dimensão da "escolha" e da "liberdade" individual prevalece nas representações e práticas que envolvem a experiência reprodutiva contemporânea, assim como a pílula anticoncepcional representou avanço ao favorecer a contracepção, mais recentemente as técnicas de reprodução humana assistida, com significativos avanços na área da biomedicina, ampliaram as

\footnotetext{
${ }^{18}$ Podemos encontrar uma discussão sobre a categoria casal do ponto de vista sociológico em Heilborn (2004).
} 
possibilidades conceptivas. Cabe ressaltar que as ações de planejamento familiar, no contexto da saúde, seguem no sentido de assegurar apenas seu conteúdo negativo deste direito à opção, comportando apenas os recursos à contracepção ou seja, assegura o direito de não ter filhos.

No entanto, o sentido mais contemporâneo dos direitos reprodutivos contempla o conteúdo positivo da escolha reprodutiva, ensejando incluir nesta escolha 0 "como" reproduzir (BARBOZA, 2004), trata-se de tornar possível a concepção que valorize a decisão do casal e do indivíduo. Ocorre, no entanto, que mesmo após mais de três décadas do nascimento do primeiro bebê de proveta, 0 Brasil continua sem lei em sentido formal capaz de pacificar os dissensos que ainda existem em torno do uso de tais tecnologias. Permanecem no cenário apenas as orientações éticas do Conselho Federal de Medicina que segue ocupando este vazio legislativo, o que não acontece sem tensões e conflitos relacionados ao lugar que ocupa na cena social.

Tendo em vista os aspectos assinalados, cabe considerar o desamparo legal experimentado pelos casais e indivíduos que acionam os recursos médicos ao decidir terem filhos, decorrente da ausência de legislação, mas, sobretudo pela não recusa por parte da sociedade de um modelo único de referência para constituição de família e dos laços de filiação. Imprescindível reconhecer que este modelo cedeu espaço à liberdade individual de se optar inclusive por não se ter família ou, ainda, de se ter filhos de modo independente da existência de um(a) companheiro(a), e independente da orientação sexual. Há práticas sociais que não podem mais continuar sendo consideradas novas, mas continuam causando polêmica e dissensos, daí a necessidade de ampliação do debate.

Por fim, ponderamos que a atividade sexual heterossexual tem sido pouco investigada em pesquisas sobre sexualidade comparativamente à homossexual, possivelmente em decorrência da relevância política atual dos estudos sobre a diversidade sexual, impulsionadas pelo avanço da epidemia do HIV/Aids. Também a reprodução no contexto da conjugalidade homossexual no recurso às tecnologias reprodutivas tem sido menos estudada do que no contexto da conjugalidade heterossexual relacionada a estes procedimentos. Ademais a indicação nas instâncias decisórias e regulatórias, no plano dos direitos, de haver uma indistinção entre as entidades familiares, seja relativas ao par hetero ou homossexual, parece distante da realidade dos casais e dos indivíduos. Portanto, visando cotejar os diferentes contextos sociais e culturais modeladores das concepções e práticas corporais contemporâneas, parece-nos merecer uma maior atenção nos estudos sobre sexualidades um conjunto de práticas reprodutivas, 
exercidas por indivíduos ou casais, visando uma maior compreensão dos nexos entre gênero, sexualidade e a dimensão reprodutiva do corpo.

\section{REFERÊNCIAS}

CORRÊA, Marilena. Vilela. Novas Tecnologias reprodutivas: limites da biologia ou biologia sem limites? Rio de Janeiro: EdUERJ, 2001. 264p.

BARBOZA, Heloísa Helena. Direito à procriação e as técnicas de reprodução assistida. In: Eduardo de Oliveira Leite. (Org.). Bioética e Biodireito: Aspectos Jurídicos e Metajurídicos. 1ed. Rio de Janeiro: Forense, 2004, p. 153-168.

BENEDITO, Ailton. MPF/GO aciona CFM por causa de resolução que trata de reprodução assistida. JusBrasil notícias. Disponível em:

$<$ http://mpf.jusbrasil.com.br/noticias/100549084/mpf-go-aciona-cfm-por-causade-resolucao-que-trata-da-reproducao-assistida > Acesso em: 15 nov. 2014.

BOZON, Michel. Sexualidade, conjugalidade e relações de gênero na época contemporânea. Interseções - Revista de Estudos Interdisciplinares, Rio de Janeiro, jul/dez, n. 3, v. 2, p. 133-145, 2001.

BRASIL, Presidência da República, 2009. Disponível em:

$<$ www.planalto.gov.br/ccivil_03/_ato2007-2010/2009/lei/112010.htm> Acesso em: 10 dez. 2014.

COSTA, Maria Cecília Solheid. Os "filhos do coração": adoção em camadas médias. 1988. 314p. Tese (Doutorado em Antropologia Social) - Museu Nacional, Universidade Federal do Rio de Janeiro, Rio de Janeiro, 1988.

DAUSTER, Tania. A experiência "obrigatória" - uma interpretação sobre a maternidade fora do casamento em camadas médias urbanas. Boletim do Museu Nacional. Nova série, Rio de Janeiro, n. 59, dezembro, 1988.

DE SINGLY, François. 0 Nascimento do "Indivíduo Individualizado" e seus efeitos na vida conjugal e familiar. In: PEIXOTO, Clarice Ehlers, DE SINGLY, Françoise. \& CICCHELLI, Vicenzo. Família e Individualização. Rio de Janeiro: Editora FGV, 2000. p.13-9.

DINIZ, Débora. Introdução. In: DINIZ, Debora \& BUGLIONE, Samantha (Orgs.). Quem pode ter acesso às tecnologias reprodutivas? Diferentes Perspectivas do Direito Brasileiro. Brasília: Letras Livres, 2002. p.9-21. 
FACHIN, Rosana. Do parentesco e da Filiação. In: (Orgs.) DIAS, Maria Berenice e PEREIRA. Rodrigo da Cunha. Direito de Família e o novo Código Civil. Belo Horizonte: Del Rey, 2006.

FONSECA, Claudia. A certeza que pariu a dúvida: paternidade e DNA. Estudos Feministas, Florianópolis, v.12, n. 2, p. 13-34, 2004.

FONSECA, Claudia. Abandono, adoção e anonimato: Questões de moralidade materna suscitadas pelas propostas legais de parto anônimo. Sexualidade, Saúde, Sociedade - Revista Latino-Americana, v. 1, p. 30-62, 2009.

FOUCAULT, Michel. História da Sexualidade I. A Vontade de Saber. 12a ed. Rio de Janeiro: Edições Graal, 1997.

GROSSI, Miriam. PORTO, Rozeli Maria. \& TAMANINI, Marlene. (Orgs.). Novas tecnologias reprodutivas conceptivas: questões e desafios. Brasília: Letras Livres, 2003. 196p

HEILBORN, Maria Luiza. Dois é par: Gênero e identidade sexual em contexto igualitário. Rio de Janeiro: Editora Garamond, 2004. 217p.

KNIBIEHLER, Yvonne. Introduction: la construction sociale de la maternité. In: KNIBIEHLER, Yvonne (Ed.). Maternité: affaire privée, affaire publique. Paris: Bayard. p.13-20, 2001.

LÔBO, Paulo Luiz Neto. Famílias. Rio de janeiro: Editora Saraiva, 2012.432p.

LUNA, Naara. Pessoa e parentesco nas novas tecnologias reprodutivas. Revista Estudos Feministas, Florianópolis, vol. 9, n. 2, p. 389- 413, 2001.

MANICA, Daniela Tonelli. A desnaturalização da menstruação: hormônios contraceptivos e tecnociência. Horiz. antropol., Porto Alegre, v. 17, n. 35, June 2011.

MELLO, Luiz. Novas Famílias: conjugalidade homossexual no Brasil contemporâneo. Rio de Janeiro: Garamond, 2005. 232p.

MOÁS, Luciane. O Reconhecimento Jurídico da Família Homoafetiva: uma questão de justiça. Tese de doutorado. Universidade do Estado do Rio de Janeiro. Instituto de Medicina Social, 2006.

MOÁS, Luciane \& VARGAS, Eliane. Princípios jurídicos e aspectos normativos em saúde implicados no acesso à reprodução assistida no âmbito conjugal: revisitando parâmetros. In: TAQUETTE, Stella; CALDAS, Célia. (Org.). Ética em pesquisa com populações vulneráveis. $1^{\mathrm{a}} \mathrm{ed}$. Rio de Janeiro: EdUERJ, 2012, v. II, p. 239-265. 
MORAES, Maria Celina Bodin. Na medida da pessoa Humana: estudos de direito civil. Rio de Janeiro: Renovar, 2010.

NOVAES, Simone. \& SALEM, Tania. Recontextualizando o embrião. Estudos Feministas, Rio de Janeiro, v. 1, n. 3, p. 65-88, 1995.

PEIXOTO, Clarice Ehlers. Avós e netos na França e no Brasil: a individualização das transmissões afetivas e materiais. In: PEIXOTO, Clarice Ehlers, DE SINGLY, Françoise. \& CICCHELLI, Vicenzo. Família e Individualização. Rio de Janeiro: Editora FGV, 2000. p. 95-111.

PEREIRA, Tania da Silva. Da Adoção. In: (Orgs.) DIAS, Maria Berenice e PEREIRA, Rodrigo da Cunha. Direito de Família e o Novo Código Civil. Belo Horizonte: Del Rey, 2011, 4 edição.

RAMÍREZ-GÁLVEZ, Martha. Novas Tecnologias Reprodutivas Conceptivas: fabricando a vida, fabricando o futuro. 2003. 259 p. Tese (Doutorado em Ciências Sociais) - Instituto de Filosofia e Ciências Humanas, Universidade Estadual de Campinas, Campinas, 2003.

RAMÍREZ-GÁLVEZ, Martha. Inscrito nos genes ou escrito nas estrelas? Adoção de crianças e uso de Reprodução Assistida. Revista de Antropologia, São Paulo, v. 54, p. 47-87, 2011.

SALEM, Tania. 0 princípio do Anonimato na Inseminação Artificial com Doador (IAD): Das Tensões entre Natureza e Cultura. Physis - Revista de Saúde Coletiva, Rio de Janeiro, v. 5, n. 1, p. 33-68, 1995.

SOUZA, Érica Renata. Maternidade Lésbica e Novas Tecnologias Reprodutivas: um relato sobre casos canadenses. In: FERREIRA, Verônica; ÁVILA, Maria Betânia \& PORTELA, Ana Paula (Orgs.). Feminismo e Novas Tecnologias Reprodutivas. Recife: SOS Corpo - Instituto Feminista para a Democracia. p.136-163, 2006.

STRATHERN, Marilyn. Reproducing the future: Essays on Anthropology, kinship and the new reproductive technologies Manchester. Manchester: Manchester University Press, 1992. 200p

STOLCKE, Verena. El Sexo de la Biotechnology. Estudos Feministas, Rio de Janeiro, v.6, n.1, p. 139-155, 1998.

TAMANINI, Marlene. Produções tecnológicas e biomédicas e seus efeitos produtivos e prescritivos nas práticas sociais e de gênero. Cadernos IHU Idéias. Rio Grande do Sul: UNISINOS, v. 11, p. 1-24. 2013. 
TAMANINI, Marlene. Reprodução assistida e gênero: o olhar das ciências humanas. $1^{\mathrm{a}}$ ed. Florianópolis: UFSC/SC, 2009. v. 1. 312p .

TARNOVSKI, Flávio Luiz. "Pai é tudo igual?": significados da paternidade para homens que se autodefinem como homossexuais. In: PISCITELLI, Adriana.; GREGORI, Maria Filomena, CARRARA, Sérgio (Org.). Sexualidade e saberes: convenções e fronteiras. Rio de Janeiro: Garamond. p. 385-414. 2004.

VARGAS, Eliane. A Figueira do Inferno: os reveses da identidade feminina. Revista Estudos Feministas, UFSC/Santa Catarina, v. 7, 1999.

VARGAS, Eliane. "Casal infértil': usos e valores do desejo de filhos entre casais de camadas médias no Rio de Janeiro". 272 p. [Tese de Doutorado em Saúde Coletiva]. Rio de Janeiro: Instituto de Medicinal Social, UERJ, 2006.

VARGAS, Eliane. "Barrigão à mostra": vicissitudes e valorização do corpo reprodutivo na construção das imagens da gravidez. História, Ciências, SaúdeManguinhos, Rio de Janeiro, v. 19, n. 1, Mar. 2012.

VARGAS, Eliane, \& MOÁS, Luciane. Discursos normativos sobre o desejo de ter filhos. Revista de Saúde Pública (USP. Impresso), v. 44, p. 758-762, 2010.

VARGAS, Eliane \& MOÁS, Luciane. Gênero e sexualidade na cena das políticas brasileiras: das afinidades eletivas e (in)visibilidades na agenda pública. Dossiê reflexões sócio-antropológicas acerca das políticas públicas sobre gênero e sexualidade. Século XXI - Revista de Ciências Sociais, v.4, n.2, 2014.

VARGAS, Eliane; RUSSO, Jane A.; HEILBORN, Maria Luiza. Sexualidade e reprodução: usos e valores relativos ao desejo de filhos entre casais de camadas médias no Rio de Janeiro, Brasil. Cad. Saúde Pública, Rio de Janeiro, v. 26, n. 1 , jan. 2010.

UZIEL, Anna Paula. Homossexualidade e adoção. Rio de Janeiro: Garamond; 2007. p. 224. 